\title{
A escola e a exploração do trabalho infantil na fumicultura catarinense
}

\author{
Soraya Franzoni Conde*
}

Célia Regina Vendramini**

\section{Resumo}

O objetivo deste artigo é refletir sobre as relaçóes entre a escola e a exploração do trabalho infantil no contexto da fumicultura catarinense, considerando as particularidades e os aspectos universais a que os trabalhadores do campo estáo submetidos. A pesquisa foi realizada em 11 escolas, com a participação de 1080 crianças e adolescentes dos municípios catarinenses de São Bonifácio, Imbuia e Canoinhas. Observou-se que a existência de uma tênue fronteira entre o trabalho da criança e a ajuda à organização da vida familiar é um elemento fundamental das atuais formas de exploraçáo e generalização do trabalho coletivo. Dessa forma, o lugar ocupado pela escola no campo vai além do ensino e da qualificação necessária ao trabalho na sociedade capitalista. A escola e as unidades de educação infantil são também, dialeticamente, o local do não trabalho, onde as crianças e os adolescentes são poupados da labuta diária, encontram colegas da mesma idade, brincam, aprendem e descansam.

Palavras-chave: Trabalho Infantil. Escola. Campo.

\footnotetext{
* Doutora em Educação pela Universidade Federal de Santa Catarina (UFSC). Professora do Departamento de Estudos Especializados em Educação, do Programa de Pós-graduação em Educação e colaboradora no Programa de Pós-graduação em Serviço Social da Universidade Federal de Santa Catarina (UFSC).

** Doutora em Educaçáo pela Universidade Federal de São Carlos (UFSCAR). Professora do Departamento de Estudos Especializados em Educação e do Programa de Pós-graduação em Educaçâao da Universidade Federal de Santa Catarina (UFSC).
} 


\section{Apresentação}

São os tempos modernos, cunhado, mas não se apoquente: mudam os títulos - coronel é doutor, capataz é gerente, fazenda é empresa -, o resto não muda, riqueza é riqueza, pobreza é pobreza com fartum de desgraça. (Jorge Amado).

O problema da exploração do trabalho infantil é abordado por divergentes perspectivas teóricas. Se por lado, há quem defenda que a escola, a educação e os programas de transferência de renda podem erradicar o problema da exploração de crianças e de adolescentes (KASSOUF, 2003), por outro, há quem entenda que a exploração do trabalho infantil persistirá enquanto houver exploração de mais valor (MARX, 1988; THOMPSON, 2002; MÉSZÁROS, 2005). Para o primeiro grupo, a ampliação da escolarização, por meio de iniciativas como a escola em tempo integral e de programas de transferência de renda que obrigam as crianças a frequentarem a escola, seria solução à exploração infantil no trabalho, uma vez que estando na escola as crianças náo poderiam ocupar o tempo em trabalhar e teriam condiçóes de no futuro encontrarem bons empregos, terem bons salários e não destinarem aos seus filhos o trabalho precoce. Sendo assim, os dados de pesquisa expostos neste artigo ${ }^{1}$ evidenciam a insuficiência de tais açóes e mostram que quando há necessidade de contribuição à sobrevivência familiar, as crianças combinam escola e trabalho gerando prejuízos ao desenvolvimento humano pleno, bem como à aprendizagem. Essas questóes evidenciam a necessidade de maior aprofundamento teórico e empírico sobre a temática, pois se a escola não é solução aos problemas decorrentes da materialidade, ela é um espaço importante da formação humana podendo servir tanto à qualificação necessária à reprodução do sistema capitalista quanto à apropriação dos avanços sociais e científicos capaz de constituir seres críticos às relaçóes sociais vigentes.

Neste artigo, objetivamos refletir sobre as circunstâncias em que a exploraçáo do trabalho infantil e a ajuda da criança ocorrem na fumicultura catarinense e se relacionam com a escolarização, considerando as particularidades e os aspectos universais, históricos e sociais a que as famílias trabalhadoras do campo estáo submetidas no interior de Santa Catarina.

$\mathrm{Na}$ atualidade, a persistência da exploração de crianças no trabalho no campo e na cidade é indicada pelos dados do Instituto Brasileiro de Geografia e Estatística (IBGE) (BRASIL, 2012), que mostram que 3,4 milhóes de crianças e de adolescentes (entre 5 e 17 anos) trabalham no Brasil, o que representa 8,6\% da população na faixa etária correspondente. Das crianças e dos adolescentes ocupados, 31\% estão inseridos em trabalhos agrícolas, proporção que chega a 60,2\% entre 5 e 13 anos. Santa Catarina 
ocupa o $4^{\circ}$ lugar entre os estados brasileiros com maior índice de trabalho infantil e possui 32 das 100 cidades brasileiras que compóem o ranking do trabalho infantil. Destaca-se o município catarinense de Novo Horizonte que ocupa o $1^{\circ}$ lugar nacional, pois $70 \%$ das crianças e dos adolescentes trabalham no campo. Ainda segundo o IBGE (BRASIL, 2012), a renda média das famílias cujas crianças trabalham é de $\mathrm{R} \$ 512,00$, o que localiza o trabalho infantil entre classes sociais desfavorecidas economicamente. Entre as crianças trabalhadoras, $80 \%$ frequentam a escola, o que evidencia que frequência escolar é insuficiente para retirar as crianças do trabalho.

Entre as denominadas piores formas de trabalho infantil ${ }^{2}$, encontra-se o trabalho realizado na fumicultura, onde ao mesmo tempo em que a contribuiçâo da criança se insere em formas artesanais de socialização e de educação familiar, recebendo a conotação de atividade educativa, ele ocorre em relaçóes de trabalho integradas às empresas multinacionais capitalistas. Para os agricultores, a inserção de crianças e adolescentes no trabalho do campo é o meio pelo qual ensinam os "saberes da terra", numa lembrança saudosista às formas artesanais de aprendizagem anteriores ao trabalho produtor de mais-valia e à forma industrial de produção.

Assim sendo, neste artigo, primeiramente, relatamos os caminhos metodológicos da pesquisa realizada nos municípios catarinenses de São Bonifácio, Imbuia e Canoinhas. Em seguida, abordamos a exploraçáo do trabalho na fumicultura e a cadeia produtiva do fumo onde o trabalho da criança se relaciona à totalidade social. Por último, tratamos dos dados da pesquisa empírica, refletindo sobre a forma dissimulada em que o trabalho infantil aparece como ajuda e suas relaçóes com a escolarização.

\section{Caminhos da pesquisa}

A pesquisa foi realizada por meio do cruzamento dos seguintes instrumentos: revisão bibliográfica, análise de dados oficiais, relatórios de fiscalização do trabalho infantil, entrevistas com pesquisadores, sindicalistas, trabalhadores rurais e fiscais do trabalho. Além disso, recolhemos produçóes textuais e depoimentos de 1080 crianças e adolescentes, entre 5 e 17 anos, de onze escolas públicas ${ }^{3}$, localizadas nos municípios catarinenses de São Bonifácio, Imbuia e Canoinhas. As crianças da educação infantil e dos primeiro e segundo anos do ensino fundamental foram convidadas a desenhar. Para o desenvolvimento da investigaçáo dentro das escolas e das unidades de educação infantil, contamos com a mediação e com o auxílio dos docentes das escolas públicas pesquisadas.

Os três municípios que compóem a amostra da pesquisa são produtores de fumo e aparecem nos dados da Superintendência Regional do Trabalho com recentes 
denúncias de trabalho infantil. O município de Canoinhas é o principal produtor de fumo do estado e faz parte de uma região com constantes denúncias de crianças no trabalho. Imbuia é um município que, embora pequeno, tem como principal atividade econômica a fumicultura e possui um dos Índices de Desenvolvimento Humano (IDHs) mais baixos de Santa Catarina. Já São Bonifácio teve a fumicultura como principal atividade econômica na década de 1980, lugar ocupado, na atualidade, pela avicultura e pela produçáo de laticínios. Percebemos, portanto, que os três municípios possuem características diferentes e se encontram em momentos distintos na história que desenvolvem com a produção do fumo.

Tendo em vista a ilegalidade envolvida no trabalho infantil, as famílias agricultoras temem falar sobre o trabalho de seus filhos em suas propriedades e sofrer ação punitiva dos fiscais do Ministério do Trabalho e do Emprego (MTE) e da Associação dos Fumicultores do Brasil (Afubra). Há casos de famílias produtoras de fumo que não tiveram suas produçóes compradas pela indústria fumageira em virtude da fiscalização ter encontrado crianças trabalhando na propriedade em anos anteriores. Por isso, sempre que perguntamos diretamente para as famílias trabalhadoras do campo se as crianças trabalham, a resposta é negativa: "às vezes eles me ajudam um pouco, mas trabalhar não". Entretanto, analisando o que revelam os textos e os desenhos das crianças coletados dentro das instituiçôes, descobrimos que a ajuda infantil é, na verdade, trabalho.

Com isso, do ponto de vista metodológico, percebemos que a apreensão do trabalho infantil exige ir além da aparência imediata e cotidiana do fenômeno que tende a responsabilizar individualmente as famílias pelo trabalho de seus filhos. O trabalho de crianças é síntese de múltiplas determinaçôes. Se os pais escondem o trabalho infantil e, ao mesmo tempo, consentem que seus filhos trabalhem, essa é a forma histórica que aprenderam a sobreviver enquanto classe trabalhadora. Afinal, não são as ideias que determinam o modo pelo qual os homens produzem a própria existência, mas o contrário, são as relaçôes sociais travadas entre os seres humanos que edificam suas ideias.

\section{A fumicultura}

O Brasil é o maior produtor de fumo do mundo, sendo o fumo brasileiro reconhecido pela sua qualidade superior. Apenas $15 \%$ da produção destina-se ao consumo interno e os $85 \%$ restantes são exportados, principalmente, para a Europa ${ }^{4}$. O trabalho na fumicultura ocorre, geralmente, em pequenas propriedades agrícolas familiares e é caracterizado por jornadas exaustivas no período de colheita, controle 
técnico da qualidade e da quantidade da produçâo (pela empresa integradora que compra a produçáo), constante contato com agrotóxico e com a nicotina absorvida pela pele. O contato direto com a folha de fumo acarreta uma doença popularmente chamada de "mancha verde".

A contratação da força de trabalho é a parte mais cara da produção de fumo, por isso, a gestão empresarial capitalista opta pela produção integrada. As famílias numerosas são os alvos preferidos da indústria. A negociação contratual é realizada entre adultos, mas o trabalho é desenvolvido no âmbito familiar e, assim, muitas regras da produção seguem o que é convencionado no âmbito privado, como, por exemplo, a submissão dos mais novos (geralmente crianças, adolescentes e jovens) aos mais velhos. No trabalho da colheita do pé de fumo, o trabalhador necessita colher as folhas, aparálas, pendurá-las nas estufas para secar, separar e enrolar a manilha. Na estufa, é preciso controlar rigorosamente a temperatura e a umidade das folhas para garantia de qualidade do produto. As famílias trabalham de manhã, de tarde e até durante a noite. Caso a empresa fumageira resolvesse contratar trabalhadores pagos por jornada de trabalho, seguindo as determinaçôes legais trabalhistas, o custo da produção seria muito alto. O trabalhador (ou melhor, a sua família) tem que alcançar as cotas com a qualidade determinada pela empresa. Quando pressionadas em relação às constantes denúncias de exploração do trabalho infantil, as empresas fumageiras afirmam que o problema do trabalho infantil é cultural no campo e deve ser solucionado na particularidade de cada família.

Conforme Francisco de Oliveira (2003), a exploração do trabalho de crianças é reflexo da forma como o capitalismo se reproduz em sua periferia. Desde os primórdios da relação capital, as formas artesanais são combinadas com tecnologia de ponta. No caso específico da fumicultura, a coleta da folha deve ser cuidadosa e manual para manter a qualidade. A redução do custo da produção é garantida pela redução do valor pago à força de trabalho.

Caio Prado Junior (2005) critica a teoria do subdesenvolvimento do Brasil, alegando que os problemas que afetam os trabalhadores rurais são resquícios de relaçôes sociais escravocratas, desenvolvida pelas forças do capitalismo nascente na Europa e expandida para o Brasil e para o mundo por meio das companhias de colonização e exploração das matérias-primas necessárias à acumulaçáo primitiva do capitalismo europeu.

O trabalho domiciliar conjugado com o trabalho assalariado existe desde os primórdios do sistema capitalista na Inglaterra. Para Marx (1988), a produção capitalista do século XIX movimenta por fios invisíveis trabalhos familiares, realizados em espaços privados, por sistema de produtividade, e nele toda a família, incluindo as 
crianças, trabalham na produção. Portanto, desde o nascimento da produção capitalista, o trabalho familiar está presente nas diversas formas de assalariamento. Há setores, semelhantes às atuais produçôes de fumo em Santa Catarina, em que o valor da força de trabalho é tão baixo que náo compensa o investimento em maquinaria de ponta, mas isso não significa ausência da relação social capitalista e nem de indústria.

Para Francisco de Oliveira (2003), as ações na agricultura desempenham um papel fundamental na industrialização e na constituição do capitalismo nacional. Para o autor, persistem formas peculiares e primitivas de subsistência como parte do desenvolvimento moderno, com rebaixamento do custo da força de trabalho, base da acumulação. Essa situação é parte de um processo acelerado de desenvolvimento onde crianças trabalhando na colheita do fumo não são sinais de atraso e subdesenvolvimento do campo, mas uma forma atroz de modernização:

De fato o processo real mostra uma simbiose e uma organicidade, uma unidade de contrários, em que o chamado "moderno" cresce e se alimenta da existência do "atrasado" [...]. tal postulação esquece que o subdesenvolvimento é precisamente uma produçáo da expansão do capitalismo [...]. A ênfase no aspecto da dependência do subdesenvolvimento com relação ao desenvolvido, deixa de abordar aspectos internos da estrutura de dominaçáo. O problema se torna como que uma oposição entre naçóes, esquecendo que o problema do desenvolvimento se relaciona à oposiçáo entre classes sociais internas [...]. A atenção é desviada da luta de classes. (OLIVEIRA, 2003, p. 32-34).

Tanto no caso da economia familiar quanto na venda ambulante que garante o escoamento das mercadorias produzidas, o trabalho da criança é fundamental e aparentemente associado a uma relação de aprendizagem entre pais e filhos. $\mathrm{Na}$ realidade, tratam-se das formas atuais da industrialização, ligadas por vários braços a exportadores, embaladores, laboratórios de pesquisa, proprietários rurais e projetos educacionais cujo investimento garante à empresa subsídios fiscais e uma imagem de socialmente responsável.

As empresas responsáveis pela exploração familiar integrada no fumo desenvolvem programas de educação para as crianças, com intuito de retirá-las do trabalho precoce, sem, contudo, melhorar a condiçáo de vida familiar. Assim, as empresas financiadoras passam a controlar a formação que o trabalhador recebe. Acolá, os programas servem de marketing empresarial promovendo uma imagem de "empresa amiga da criança" o que favorece a aceitação de seus produtos no mercado nacional e, 
principalmente, internacional. Na escola, a empresa controla o currículo e fornece uma formação de acordo com seus interesses.

Em uma escola pesquisada no município de São Bonifácio, encontramos uma funcionária que planta fumo há cinco anos. Ela tem cerca de 50 mil pés de fumo e trabalha na escola meio período. Conta que começou a trabalhar na roça desde pequenina. Acha que na atualidade as coisas são diferentes da época da sua infância, pois a lei não deixa as crianças irem para a roça:

A lei diz que até 18 anos não pode ir para a roça. Mas, até lá vai fazer o quê? Como eles vão saber trabalhar aos 18 anos se não nos acompanharem na roça? Hoje, as crianças vão para a roça, porque também não podem ficar sozinhas em casa. Na roça, um cuida do outro e o tempo passa mais rápido. Também aqui no campo não há escola. Não há creche. As crianças têm que irjunto com ospais 5 .

A ausência de escolas de educação infantil no campo é uma realidade problematizada pelas trabalhadoras rurais que acabam levando as crianças para o trabalho na roça. Além disso, observamos casos em que crianças, entre 0 e 5 anos, frequentam escolas de ensino fundamental multisseriadas, contrariando as legisçóes existentes e desconsiderando as especificidades do desenvolvimento das crianças pequeninas e das que frequantam o ensino fundamental.

\section{O que dizem os dados}

Entre as 1080 crianças da amostra pesquisada, 416 (38,5\%) são do município de Imbuia, 341 (31,5\%) de Canoinhas e 323 (29,9\%) de São Bonifácio. Com relação ao sexo, $575(53,2 \%)$ são do sexo feminino e 505 (46,7\%) do sexo masculino. A pesquisa abrangeu crianças e adolescentes com idades entre 9 e 16 anos, sendo que as crianças da educação infantil e das primeira e segunda séries do ensino fundamental, ao invés de escreverem, foram convidadas a desenhar sobre o que fazem fora da escola.

A partir das variáveis encontradas nas leituras das redaçóes coletadas, percebemos que as crianças que trabalham desenvolvem diferentes tipos de atividades em distintas relaçóes que compóem a forma como a mercadoria força de trabalho infantil é explorada no seio da família. Essas atividades podem ocorrer na própria propriedade rural familiar (trabalho rural familiar); podem ser domésticas e familiares enquanto os pais trabalham na roça (trabalho doméstico familiar); podem se desenvolver em propriedades alheias de amigos ou parentes da vizinhança (trabalho rural não familiar); em casas alheias não familiares (trabalho doméstico náo familiar); podem ocorrer outros tipos de atividades de trabalho em contextos não 
familiares, como, por exemplo, trabalho em madeireira, oficinas mecânicas, lojas, fábrica de laticínios (outro trabalho náo familiar); em atividades que consideramos como realmente de ajuda na organizaçáo da vida familiar, como tirar a mesa e lavar a louça após o almoço ou arrumar o próprio quarto e os brinquedos (organizaçáo à vida familiar); podem ocorrer ainda combinaçôes entre o trabalho na roça e o doméstico, pois há casos de crianças e adolescentes que no período de aulas são responsáveis pela comida, roupa e limpeza doméstica, e durante as férias vão à roça trabalhar na colheita do fumo e/ou outra cultura (trabalho rural + doméstico famíliar); também há combinações entre trabalhos no âmbito familiar e trabalhos no âmbito não familiar, pois há crianças que, por exemplo, trabalham no comércio durante os dias da semana e, nos finais de semana e feriados, vão à roça da família ou são responsáveis pela limpeza doméstica (trabalho náo familiar + familiar); e há ainda situaçóes em que as crianças se dedicam apenas às atividades de estudo, às brincadeiras, aos esportes, à música, às artes etc. (crianças e adolescentes que afirmam náo trabalhar).

Quadro 1: Número total de crianças e adolescentes por tipo de atividade ou de trabalho

\begin{tabular}{|c|c|c|c|c|}
\hline & Frequência & Percentual & $\begin{array}{l}\text { Percentual } \\
\text { válido }\end{array}$ & $\begin{array}{l}\text { Percentual } \\
\text { acumulado }\end{array}$ \\
\hline Trabalho Rural Familiar & 348 & 32,2 & 32,2 & 32,2 \\
\hline $\begin{array}{l}\text { Trabalho Doméstico } \\
\text { Familiar }\end{array}$ & 173 & 16,0 & 16,0 & 48,2 \\
\hline $\begin{array}{l}\text { Trabalho Rural Não } \\
\text { Familiar }\end{array}$ & 18 & 1,7 & 1,7 & 49,9 \\
\hline $\begin{array}{l}\text { Trabalho Doméstico Não } \\
\text { Familiar }\end{array}$ & 7 & ,6 & ,6 & 50,6 \\
\hline $\begin{array}{l}\text { Outro Trabalho Não } \\
\text { Familiar }\end{array}$ & 54 & 5,0 & 5,0 & 55,6 \\
\hline $\begin{array}{l}\text { Organização à vida } \\
\text { familiar }\end{array}$ & 133 & 12,3 & 12,3 & 67,9 \\
\hline $\begin{array}{l}\text { Trabalho rural }+ \\
\text { doméstico familiar }\end{array}$ & 81 & 7,5 & 7,5 & 75,4 \\
\hline $\begin{array}{l}\text { Trabalho não familiar + } \\
\text { familiar }\end{array}$ & 14 & 1,3 & 1,3 & 76,7 \\
\hline $\begin{array}{l}\text { Crianças e adolescentes } \\
\text { que afirmam não trabalhar }\end{array}$ & 252 & 23,3 & 23,3 & 100,0 \\
\hline Total & 1080 & 100,0 & 100,0 & \\
\hline
\end{tabular}

Fonte: CONDE, 2012. 
Seguindo as percentagens apontadas pelo quadro 1, 32,2\% das crianças e dos adolescentes pesquisados, desenvolvem atividades rurais de trabalho; $16 \%$ realizam atividades domésticas de trabalho; $1,7 \%$ desenvolvem trabalho rural não familiar; $0,6 \%$ trabalho doméstico não familiar; $12,3 \%$ auxiliam nas tarefas para a organização da vida familiar; $7,5 \%$ combinam o trabalho doméstico cotidiano com o trabalho rural; $5 \%$ desenvolvem trabalho em locais não familiares; $1,3 \%$ combinam trabalho familiar com trabalho náo familiar, o que compóe um conjunto de $76 \%$ de crianças que desenvolvem alguma forma de trabalho. Essa diversidade de formas compóe a totalidade da mercadoria ${ }^{6}$ força de trabalho infantil.

As formas que assume a mercadoria força de trabalho infantil evidenciam diferentes combinaçôes entre trabalho familiar, não familiar, doméstico, rural e não rural. Refletem as formas como o trabalho coletivo tem se complexificado e utilizado das formas domésticas, domiciliares, rurais e urbanas para ampliar a extração da maisvalia, seja ela relativa (pela intensificação da jornada de trabalho) ou absoluta (pela ampliação da jornada de trabalho) (MARX, 1988)

Compreendemos que mesmo nos casos em que crianças e adolescentes afirmam não trabalhar, ao viverem o contexto familiar do trabalho explorado acabam, mesmo que indiretamente, reproduzindo nas brincadeiras ${ }^{7}$ e em outras atividades desenvolvidas a rotina de trabalho de sua família, não havendo como separar de maneira precisa onde começa o trabalho da família e tem início uma suposta infância. Seja brincando, estudando ou trabalhando diretamente na roça, as crianças da classe trabalhadora têm a rotina de vida voltada à necessidade de reprodução da vida familiar.

O trabalho infantil doméstico, seja ele familiar (16\%), não familiar $(0,6 \%)$ ou combinado com o trabalho rural $(7,5 \%)$, envolve $261(24,1 \%)$ crianças e adolescentes da amostra. Esses dados evidenciam uma tendência que intitulamos de trabalho invisível, uma vez que a proibição do trabalho das crianças e dos adolescentes e o medo das ações punitivas da fiscalização tendem a desviá-lo para o âmbito privado, domiciliar, de difícil visualização e fiscalização, facilmente confundida como a ajuda (CONDE, 2012), como ilustram os casos abaixo que classificamos de trabalho doméstico familiar (1) e de trabalho rural + doméstico familiar (2):

1) [...] Nos finais de semana, minha mäe sai para trabalhar às 7:30hs da manhã. Ela trabalha até no sábado porque éseparada do meu pai. Então, no sábado eu faço bastante o serviço da casa e depois que eu termino vou assistir televisão ou jogar bola ${ }^{8}$.

2) De manhä, eu acordo e vou para a escola aprender coisas novas. Às 11 horas, volto para a casa e almoço e levo meu irmão no ponto de ônibus para ele ir à escola. Chego em casa lavo a louça e depois 
vamos à lavoura. Temos que limpar e plantar. Depois tomamos um chimarrão e vamos para a horta. À noite assistimos um pouco de televisão. Quando chega nos finais de semana, limpamos a nossa casa e no domingo descansamos. Nas férias escolares, chega a época de colheita e colhemos milho, feijão, batatinha, fumo e outras coisas $[\ldots]^{9}$.

Ao verificar a rotina, por meio da leitura das redaçóes, notamos que, para muitas crianças e adolescentes, as atividades em casa e na roça vão além daquilo que os adultos intitulam de ajuda. Já, para outras crianças, a rotina inclui, além do tempo de brincar e de estudar, a ajuda em tarefas de organização da vida familiar (arrumar a cama, lavar a louça após as refeiçóes, organizar os objetos pessoais etc.). Assim, diferenciamos o trabalho infantil explorado (intitulado de ajuda pelos sujeitos pesquisados) da ajuda nas tarefas de organização da vida familiar. Enquanto nos casos de auxílio nas tarefas de organização da vida familiar o tempo de estudar e de brincar náo é comprometido, nos casos de trabalho infantil explorado, o tempo que deveria ser destinado às atividades de estudo, de lazer e de infância é subtraído pelo tempo de trabalho.

Para exemplificar o que intitulamos de crianças e adolescentes que afirmam náo trabalhar $(23,3 \%$ da amostra), reproduzimos o trecho de redação redigida por uma criança de 8 anos de idade que relata uma inusitada aventura num passeio pela roça:

Eu brinco de bicicleta e faço as tarefas de casa. Vou na casa da minha avó e ela me compra chup-chup e me dá um monte de bala. Quando meu primo está lá, vamos andar de bicicleta e damos um monte de sustos nela. Uma vez eu dei um susto na minha avó e ela quase desmaiou!!! Depois meu pai foi para a venda e eu e meu primo saimos de bicicleta para tomar banho gelado de rio. Depois fui para casa e meu cachorro quase me mordeu! Fui brincar de bicicleta e meu cachorro foi atrás. Onde eu ia de bicicleta, ele ia atrás. De repente, parou na frente da bicicleta e eu levei um tombo. A bicicleta virou, eu pulei dela, of freio quebrou e ficou pendurado na roda. Eu cai, me machuquei, arranhei a bicicleta e furou o pneu da frente. Foi uma aventura daquelas $[\ldots]^{10}$.

Como podemos perceber as crianças e os adolescentes que afirmam náo trabalhar e aqueles que afirmam ajudar nas tarefas para organização da vida familiar destoam significativamente daqueles que são explorados por meio do trabalho infantil. O depoimento a seguir permite identificar, pelo desenho e pela escrita (imagem 1), como a palavra ajuda é utilizada pelos participantes da pesquisa para descrever o trabalho doméstico, historicamente desvalorizado: 
Imagem 1 - Redaçáo ilustrada por A. M.S., 10 anos, em novembro de 2010

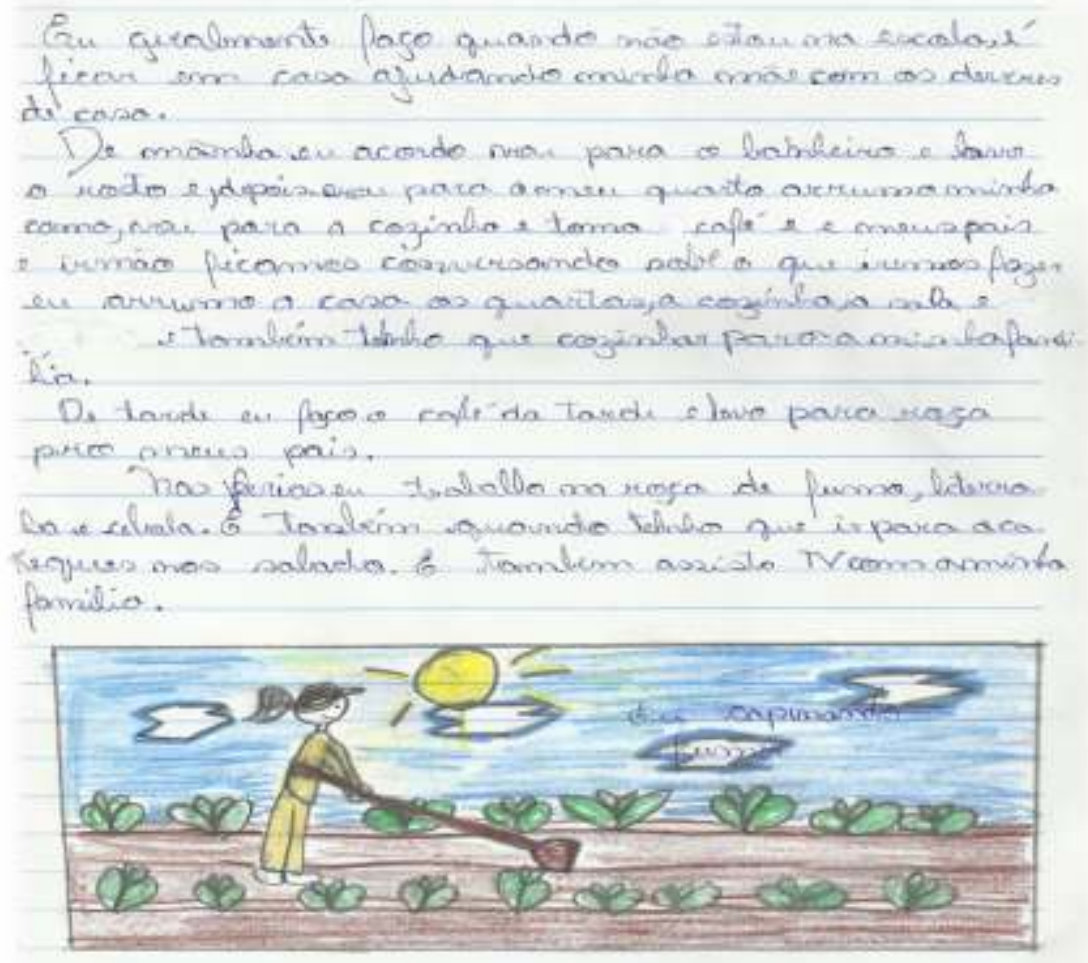

Fonte: CONDE, 2012.

Na redação, a palavra ajuda é utilizada para descrever o trabalho doméstico e a palavra trabalho é utilizada para apresentar as atividades realizadas na roça. No âmbito doméstico, a adolescente é responsável por atividades importantes à manutenção da família, como preparar o almoço, substituindo o trabalho adulto. Mas, essas responsabilidades são compreendidas, aparentemente, como ajuda. Para a fenomenologia, a forma como o objeto aparece é aquela que ele assume enquanto categoria. Já para a ciência materialista dialética, é preciso ir além da aparência imediata através da qual o objeto se manifesta, descobrindo as relaçóes que o constituem (MARX, 1989).

No depoimento a seguir, uma adolescente do município de Imbuia ilustra o que denominamos de trabalho rural familiar, que representa $32 \%$ da amostra (348 casos): 
Eu sempre levanto lá pelas $6 \mathrm{~h}$ da manhã, tiro meu pijama, vou ao banheiro. Ajudo minha mãe a tratar os bichos, galinhas, porcos, perus, coelhos. Tomo café e vou tratar as vacas. Depois, vou ao fumo para capinar e fazer outras coisas que precisam. Quando chega $11 \mathrm{~h} 30$, vou para casa almoçar, recolher as coisas da mesa e dormir um pouco. As $14 \mathrm{~h}$ voltamos para a roça. Depois das $16 \mathrm{~h}$ volto para casa, cuido das flores, tomo banho e café e vou para a escola. [...] Nas férias... nem posso chamar isso de férias... pois trabalho o dia inteiro quebrando folha de fumo. Minhas férias são um saco! Às vezes, eu fico vomitando porque me dá porre de fumo. Para mim, as férias são durante as aulas escolares, pois trabalho menos do que na chamada "férias" 1.

A criança de 10 anos trabalha na roça diariamente das 6h da manhã até as $16 \mathrm{~h}$, com pausa para almoçar entre $11 \mathrm{~h} 30$ e $14 \mathrm{~h}$, totalizando $7 \mathrm{~h} 30 \mathrm{~min}$. de jornada diária de trabalho. Após essa jornada exaustiva que envolve desde o trato de animais até capinar fumo, ela segue para a casa onde cuida das flores e vai à escola no período noturno gastar as poucas energias que lhe restam depois do dia de trabalho. Nas férias escolares, a jornada diária de trabalho é ainda mais intensa, uma vez que não há aulas e a fumicultura se encontra na época de colheita.

Vários foram os depoimentos de crianças e adolescentes que atestam gostar de ir à escola, já que podem ficar sentados, encontrar colegas da mesma idade, conversar, sorrir, jogar, brincar, estudar e aprender. A escola torna-se, dialeticamente, o local do não trabalho, o que ressalta seu papel nas políticas de combate ao trabalho infantil mesmo diante de sua incapacidade de por si só resolverem o problema.

A concorrência do trabalho no campo com o tempo de estudos é apontado como motivo para faltas e notas baixas na escola, conforme ilustra o depoimento a seguir em que um adolescente de 12 anos desenvolve trabalho rural náo familiar (18 casos ou $1,7 \%$ da amostra) nas roças de fumo, soja e milho:

Bom o que eu faço fora da escola é trabalhar e trabalhar muito. Serviço que não acaba mais. Por causa dele que tenho muitas faltas e estou em exame em algumas matérias. [...] Meu serviço é cuidar da planta de fumo, passar veneno, cultivar, capinar. Também, cuido da soja e do milho. Mas, tudo tem que passar veneno toda semana $[\ldots]^{12}$.

Geralmente, os adolescentes trabalham em um ou dois períodos e frequentam a escola no período oposto ou noturno, o que evidencia que a frequência escolar náo necessariamente retira crianças e adolescentes do trabalho. Ferro e Kassouf (2004), ao 
analisarem a eficácia de programas de transferência de renda e de combate ao trabalho infantil, percebem que as crianças não deixam de trabalhar, mas diminuem a jornada semanal de trabalho. O tempo de estudar fica espremido entre o trabalho, o descanso e o lazer, comprometendo a qualidade da aprendizagem, dado que os alunos chegam cansados à escola após o dia cheio de tarefas. Dessa forma, a finalidade de erradicação do trabalho infantil (proposta pelo PETI, por exemplo) fica delegada ao futuro pela possibilidade de quebra do ciclo da pobreza por meio do aumento da escolarização (FERRO; KASSOUF, 2004).

Destacamos que abordagens como a de Ferro e Kassouf (2004) acabam por apontar na mesma direção das políticas sociais de combate à pobreza por meio da concessão de transferência de renda que outrora criticam. Essas soluçóes, que agem na esfera aparente do problema (na etapa da circulação da mercadoria), escamoteiam que a condição da criança trabalhadora decorre da exploração do mais-valor na etapa de produção da mercadoria. Além disso, o problema do desemprego aparece como oriundo da desqualificação do trabalhador (geralmente da família da criança que trabalha) e não do desenvolvimento das forças produtivas que tende a diminuir o tempo de trabalho necessário à produção, tornando os trabalhadores descatáveis (MARX, 1988). Tais soluçôes remontam aos debates do liberalismo econômico que já no século XVIII apontavam uma educação como meio de reparar/reformar, em doses homeopáticas, os problemas decorrentes da divisão do trabalho na sociedade capitalista sem modificar a ordem estruturante (SMITH, 1989).

Para Mészáros (2005), o capital é um todo estruturado e seus defeitos não podem ser modificados superficialmente sem uma referência ao modo geral de funcionamento. Ou o sistema se impóe com êxito sobre o todo ou perde sua viabilidade como regulador dominante da reprodução metabólica universal. Limitar mudanças às margens educacionais significa abandonar uma transformação social qualitativa, assim como fazem as políticas públicas liberais direcionadas à qualificação profissional para o combate ao desemprego e o encaminhamento das crianças trabalhadoras para a escola, como se fossem as ausências de qualificação profissional e de escolarização as responsáveis por esses problemas (CONDE, 2012).

Se somarmos todos os pesquisados que trabalham, obtemos $65 \%$ entre 1080 crianças e adolescentes. Da amostra total, 13,33\% trabalham exclusivamente na fumicultura, o que evidencia que embora o contexto da pesquisa seja de crianças e adolescentes residentes em localidades fumicultoras, o trabalho ocorre em diferentes atividades rurais, domésticas, familiares e não familiares.

Em relação à jornada diária ou semanal de trabalho, os dados são reveladores. Embora $100 \%$ da amostra de crianças e adolescentes da pesquisa frequente a escola ou a unidade de educação infantil, entre os que trabalham (65\% da amostra), 34\% dedicam 
meio período ao trabalho, $23 \%$ trabalham diariamente menos de meio período e $13,52 \%$ o dia inteiro, frequentando a escola no período noturno.

Conforme a professora de Imbuia, as crianças e os adolescentes que combinam estudo e trabalho demonstram diferenças significativas:

A partir dos 11 anos já notamos uma significativa diferença entre as crianças que trabalham e as que não trabalham. A maior parte das crianças e dos adolescentes com essa idade passam a näo ter mais tempo para as tarefas em casa. A escola, por sua vez, tem que dar conta do conteúdo e de tarefas. Tentamos criar espaços de reforço e projetos para que passem o dia todo na escola estudando, mas grande parte opta pelo estudo combinado com trabalho até que em breve abandonam a escola ${ }^{13}$.

Conforme Ferraro (2009), a organização do trabalho na atualidade necessita de trabalhadores com conhecimentos gerais de leitura, escrita, cálculos e informática. Mas, esse conhecimento não pode ampliar demais a visão de mundo e de sociedade desses trabalhadores, o que, como temia Mandeville (apud Ferraro, 2009), poderia causar insubordinação, indisciplina e infelicidade diante das condiçôes de vida e de trabalho.

Nesse sentido, Mészáros (2005) diz que para pensar a educação é preciso pensar onde está o trabalho. Se a educação não é a força ideológica primária que consolida o sistema do capital, ela produz conformidade e consenso dentro dos limites legais e institucionais. Mas, mesmo diante de tais limites, não é possivel deixar de considerar que a educação age sobre as intencionalidades humanas, podendo debater problemáticas contemporâneas definindo estratégias para as mudanças sociais mais amplas.

\section{Considerações finais}

A exploração do trabalho infantil na fumicultura catarinense ocorre em pequenas propriedades agrícolas familiares. O trabalho é mediado por um contrato de integração entre empresas e o trabalhador rural que se submete às cotas, aos insumos, às técnicas e aos preços determinados pela empresa contratante. $\mathrm{O}$ trabalho da criança e do adolescente é confundido com a ajuda às tarefas familiares (aparência fenomênica que brota do objeto empírico). As crianças desenvolvem inúmeros trabalhos rurais e domésticos: dar trato aos animais, colher, plantar, podar, regar, limpar a casa, fazer comida, fazer manilhas, trabalhar na granja, na madeireira etc. As atividades são realizadas em contexto familiar e, algumas vezes, não familiar. Há ainda casos de crianças e adolescentes que combinam o trabalho familiar (nos momentos de maior 
demanda) com o trabalho não familiar (quando há menor demanda na propriedade da sua família).

Os depoimentos revelam que o lugar ocupado pelas escolas e pelas unidades de educação infantil vai além do ensino. A escola é também, dialeticamente, o local do não trabalho, onde as crianças e os adolescentes podem estar poupados da labuta diária e encontrar colegas da mesma idade para conversar, brincar, jogar, sorrir. A combinação entre escola e trabalho ocorre prejudicando o tempo de dedicaçáo aos estudos e encurta a possibilidade de ser criança e adolescente enquanto um período náo produtivo no trabalho.

Conforme os dados do IBGE (BRASIL, 2012), 80\% das crianças que trabalham no Brasil frequentam a escola o que demonstra que ela é repleta de contradiçôes. Se por um lado, a escola sozinha é ineficaz para eliminar o trabalho infantil, por outro ela garante um espaço de descanso, da brincadeira, do jogo, da aprendizagem e do encontro. Mesmo que reproduza valores e relaçôes entre as classes sociais, quando garante o espaço do ensino, socialização e da aprendizagem, acaba por instrumentalizar as classes populares à sociedade letrada, desenvolver o intelecto, o verbalismo e as boas maneiras, podendo assim, ao menos, minimizar as diferenças intelectuais entre as classes sociais. Além disso, destacamos que a educação atua nas intencionalidades humanas, podendo contribuir à crítica à forma de organização da vida social atual e visualizando possibilidades de transformá-lo.

\section{Notas}

${ }^{1}$ Este texto resulta da tese de doutorado em educação intitulada "A escola e a exploração do trabalho infantil na fumicultura catarinense", defendida no Programa de Pós-graduação em Educação da Universidade Federal de Santa Catarina. A pesquisa contou com bolsa do Fundo de Apoio e Manutenção da Educação Superior de Santa Catarina (FUMDES) e apoio do Instituto de Educação do Campo e Desenvolvimento Territorial Sustentável. Uma versão semelhante deste artigo foi aprovada para a $35^{\circ}$ Reuniáo Anual da Anped, 2012, Porto de Galinhas, PE.

2 As piores formas de trabalho infantil aparecem na classificação da Organização Internacional do Trabalho, que em sua Convenção 182 estabelece que este conceito abrange: a) todas as formas de escravidão ou práticas análogas à escravidão, como venda e tráfico de crianças, sujeição por dívidas, ser vidão, trabalho forçado ou compulsório, inclusive recrutamento forçado ou obrigatório de crianças para serem utilizadas em conflitos armados; b) 
utilização, recrutamento e oferta de criança para fins de prostituição, produção ou atuaçôes pornográficas; c) utilização, recrutamento e oferta de criança para atividades ilícitas, particularmente para a produção e tráfico de entorpecentes, conforme definidos nos tratados internacionais pertinentes; d) trabalhos que, por sua natureza ou pelas circunstâncias em que são executados, são susceptíveis de prejudicar a saúde, a segurança e a moral da criança. Essas quatro categorias integram o núcleo básico do conceito "piores formas de trabalho infantil" e devem ser priorizadas nas políticas e estratégias de combate. Para saber mais vide: <http://www.oit.org.br/sites/all/ipec/download/ conv_182.pdf>.

${ }^{3}$ No município de São Bonifácio as seguintes escolas participaram da pesquisa: Escola Básica Municipal de São Tarcísio, Escola Básica Municipal de Rio Sete, Escola Básica Municipal de Rio do Ponche. No município de Imbuia: Escola Básica Municipal Frei Manoel, Escola Básica Municipal Campo das Flores, Escola Básica Municipal Umbelina Lorenzo. Em Canoinhas: Escola Básica Municipal Alberto Wardenski, Escola Básica Municipal Maria Isabel Lima Cubas, Escola Básica Municipal Barra Mansa, Escola Básica Municipal Rio do Pinho.

${ }^{4}$ Conforme <www.afubra.com.br>.

${ }^{5}$ Entrevista concedida à Soraya Franzoni Conde em 7 de outubro de 2010.

${ }^{6}$ Para Marx (1988), a força de trabalho (adulta ou infantil) é uma mercadoria que, como as outras, é vendida no mercado em troca de dinheiro. A força de trabalho é a única mercadoria que cria mais-valor. Ela é típica da relaçáo capitalista de trabalho, caracterizada, de um lado, por trabalhadores desprovidos de qualquer propriedade (a não ser a propriedade de sua própria força de trabalho), e, de outro lado, por capitalistas proprietários dos meios de produção. Embora a troca do excedente produzido no trabalho seja anterior ao capitalismo (M-D-M), na relação social capitalista o objetivo do processo de trabalho passa a ser a produção de excedentes oriundos da exploração da força de trabalho e resultante na mais-valia. A partir de então, a mercadoria assume outra forma: M-D-M'. O M'é maior que $M$. Esse acréscimo é oriundo do tempo de trabalho que o trabalhador despendeu na produção da mercadoria e não recebeu por ele. Dessa forma, o salário náo é decorrência direta do trabalho, mas do valor socialmente necessário para a produção da mercadoria força de trabalho. Assim como as outras mercadorias, a força de trabalho tem seu valor determinado pelo tempo socialmente necessário para produzi-la, ou melhor, para manter o trabalhador vivo. 
${ }^{7}$ É importante salientar que dadas as características das brincadeiras de papéis sociais na perspectiva histórico cultural, a brincadeira não é uma atividade alucinatória que nasce do nada, naturalmente na criança, mas ela reflete a realidade e deriva das condiçóes e relaçôes concretas de vida. Ao brincar de lojinha e ser cliente ou vendedor, por exemplo, a criança busca agir de modo próximo ao que observou na realidade. Assim, a brincadeira é uma atividade social humana que supóe contextos culturais e sociais a partir dos quais a criança recria a realidade com sistemas simbólicos próprios. Tendo em vista essas características presentes na brincadeira, Vigotski (2002) afirma que a criança tem uma liberdade ilusória ao brincar, pois ela sempre segue regras implícitas ou explícitas pelas relaçóes sociais. A criança sempre procura, ao brincar, seguir as condutas sociais estabelecidas. Ou seja, mesmo brincando, a atividade da criança se desenvolve nos limites de sua classe social.

8 A. C. B., 11 anos. Depoimento concedido à Soraya Franzoni Conde em 20 de setembro de 2010.

9 B. S. W., 10 anos. Depoimento concedido à Soraya Franzoni Conde em 26 de outubro de 2010.

${ }^{10}$ F. K. H., 8 anos. Depoimento concedido à Soraya Franzoni Conde em 21 de outubro de 2010.

${ }^{11}$ M. V., 10 anos. Depoimento concedido à Soraya Franzoni Conde em 25 de novembro de 2010.

12 J. F, 12 anos. Depoimento concedido à Soraya Franzoni Conde em 19 de novembro de 2010.

13 A.S., Professora da Escola Estadual Frei Manoel de Imbuia. Entrevista concedida à Soraya Franzoni Conde em 9 de novembro de 2010.

\section{REFERÊNCIAS}

BRASIL. Instituto Brasileiro de Geografia e Estatística. Pesquisa Nacional por Amostra de Domícilio 2012. Brasília, DF, 2012. Disponível em: <www.ibge.gov.br>.

CONDE, Soraya Franzoni. A escola e a exploração do trabalho infantil na fumicultura catarinense. 2012. 191 p.Tese (Doutorado em Educação) - Universidade Federal de Santa Catarina, Florianópolis, SC, 2012.

FERRARO, Alceu R. Liberalismo e educação ou porque o Brasil não poderia ir além de Mandeville. Revista Brasileira de Educação, Rio de Janeiro, v. 14, n. 41, maio/ago. 2009. 
FERRO, Andrea Rodrigues; KASSOUF, Ana Lúcia. Avaliação dos impactos dos Programas de Bolsa Escola sobre o Trabalho Infantil no Brasil. Centro de estudos avançados em economia aplicada - ESALQ/USP, Piracicaba, SP, set. 2004.

KASSOUF, Ana Lúcia. Aspectos Socioeconômicos do Trabalho Infantil no Brasil. 2003. Tese (Pós-doutoramento em Economia) Universidade de São Paulo, Piracicaba, SP, 2003.

MARX, Karl. O Capital (crítica da economia política). São Paulo: Nova Cultural, 1988. Livro 1. v. 2.

MARX, Karl. A Ideologia Alemã. Editora Hucitec: São Paulo. 1989.

MÉSZÁROS, István. Educação para além do capital. São Paulo: Boitempo. 2005.

OLIVEIRA, Francisco. Crítica à Razão Dualista: o ornitorrinco. São Paulo:

Boitempo, 2003.

PRADO JUNIOR, Caio. A questão agrária e a revolução brasileira. In: STEDILE, João Pedro (Org.). A questão agrária no Brasil. São Paulo: Expressão Popular, 2005.

SMITH, Adam. Inquérito sobre a natureza e as causas da riqueza das naçōes. 2. ed. Lisboa. Fundação Calouste Gulbebenkian. 1989. V. 1

THOMPSON, Edward P. A formação da classe operária inglesa II (A maldição de Adão). São Paulo: Paz e Terra, 2002.

VIGOTSKI, Lev S. A formação social da mente. São Paulo: Martins Fontes, 2002. 


\section{School and exploitation of child labor in tobacco farming of Santa Catarina}

\begin{abstract}
The objective of this paper is to reflect on the relationship between school and child labor in tobacco farming context of Santa Catarina, considering the particularities and the global aspects which field workers are subjected to. The survey was conducted in 11 schools, involving 1080 children and adolescents from Santa Catarina municipalities of Sáo Bonifácio, Imbuia and Canoinhas. We noted that the existence of a fine line between child labor and aid to the family life organization is a key element of the current forms of exploitation and widespread of collective work. Thus, the place occupied by school goes beyond the field of education and skills required to work in a capitalist society. Schools and early childhood units are also, dialectically, the place of non-working, where children and adolescents are spared from the daily toil, find same age peers, play, learn and rest.
\end{abstract}

Keywords: Child Labor. School. Field.

\section{Escuela y explotación del trabajo infantil en el cultivo de tabaco catarinense}

\section{Resumen}

El objetivo de este artículo es reflexionar sobre la relación entre la escuela y el trabajo infantil en el cultivo del tabaco en el contexto de Santa Catarina, (Brasil) considerando las particularidades y los aspectos universales en que los trabajadores rurales son sometidos. La investigación fue realizada en 11 escuelas, involucrando 1.080 nińos y adolescentes de los municipios de Santa Catarina de San Bonifacio, Imbuia y Canoinhas Observamos que la existencia una tenue frontera entre el trabajo infantil y la ayuda en la organización de la vida familiar es un elemento clave de las formas actuales de explotación y del trabajo colectivo generalizado. De esta forma, el lugar que ocupa la escuela va más allá del ámbito de la educación y de la enseñanza y de las habilidades necesarias para trabajar en la sociedad capitalista. La escuela y los jardines de infancia son también, dialécticamente, el lugar del no trabajo, donde los niños y adolescentes se libran del trabajo cotidiano, y donde encuentran compañeros de la misma edad, aprenden y descansan.

Palabras claves: Trabajo Infantil. Escuela. Campo. 
Soraya Franzoni Conde

E-mail: sorayafconde@gmail.com

\section{Célia Regina Vendramini}

E-mail: celiavendram@gmail.com

Recebido em: 22/4/2014

Aprovado em: 12/8/2014 